\section{Oral-B Preis für Kinderzahnheilkunde und Prävention 2015 geht nach Jena}

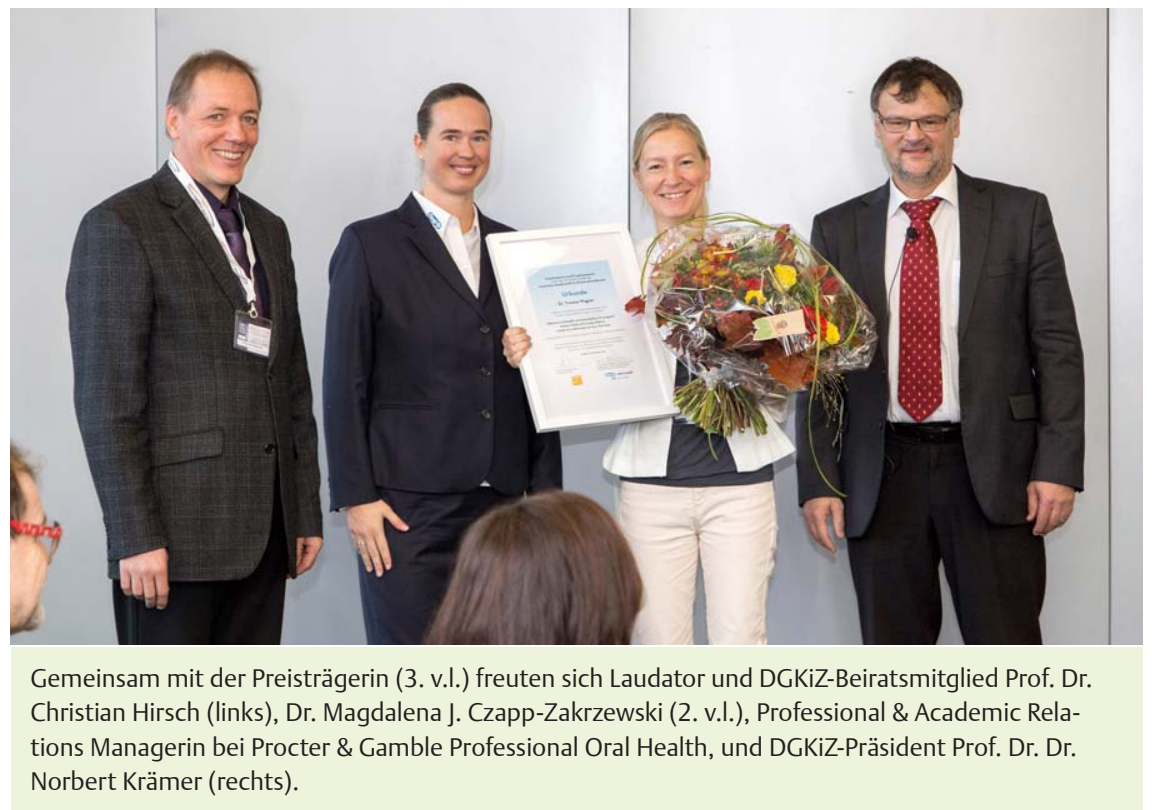

Im Rahmen der Jahrestagung der Deutschen Gesellschaft für Kinderzahnheilkunde (DGKiZ) auf dem Deutschen Zahn- ärztetag 2015 wurde am 6. November zum mittlerweile 12. Mal der Oral-B Preis für Kinderzahnheilkunde und Prävention verliehen. Mit dem 2. Platz (ein 1. und 3. Platz wurden in diesem Jahr nicht vergeben) prämiert wurde dabei der Beitrag der Arbeitsgruppe um Dr. Yvonne Wagner, Poliklinik für Präventive Zahnheilkunde und Kinderzahnheilkunde, Jena. Sie sicherte sich mit ihren Ausführungen zum Wissensstand von Hebammen in Deutschland bezüglich der Empfehlungen von zahnärztlichen Präventionsmaßnahmen das Preisgeld in Höhe von $1500 €$. Nach ihrem 1. Platz im Jahr 2011 durfte sich Dr. Wagner bei der Jahrestagung der DGKiZ schon zum 2. Mal über den Oral-B Preis für Kinderzahnheilkunde und Prävention freuen. Bei ihrer bundesweiten Online-Befragung von 947 Hebammen hatte die Arbeitsgruppe bei sehr vielen von ihnen Defizite hinsichtlich zahnmedizinischer Empfehlungen festgestellt: Lediglich 2 Drittel informierten die Mütter über frühkindliche Karies und weniger als die Hälfte empfahl den Zahnarztbesuch schon im 1. Lebensjahr. Die Forscher fanden allerdings heraus, dass 90\% der antwortenden Hebammen dazu bereit waren, sich mehr zahnmedizinisches Wissen anzueignen.

Nach einer Pressemitteilung der Procter \& Gamble Germany GmbH, Schwalbach am Taunus 